\title{
Processos judiciais como fonte de dados: poder e interpretação
}

FABIANA LUCI DE OLIVEIRA* E VIRGÍNIA FERREIRA DA SILVA**

\section{Introdução}

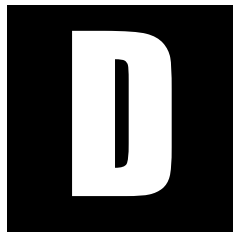

iferentes processos judiciais podem servir a diferentes tipos de pesquisa, sendo possível extrair deles análises variadas sobre grupos sociais diversos. Mas essas diferentes pesquisas têm em comum o fato de trabalharem com a interpretação da palavra escrita a fim de discorrer sobre a construção do discurso empreendido por determinados grupos sociais. Aqui vamos discutir algumas das implicações da utilização de processos judiciais a partir da experiência que tivemos em duas pesquisas diferentes: uma delas trabalha com processos criminais do fim do século XIX, ${ }^{1}$ a outra, com processos julgados pelo Supremo Tribunal Federal entre o final do século XX e o começo do século XXI. ${ }^{2}$ No primeiro caso, os grupos sociais focalizados

\footnotetext{
* Doutoranda em Ciências Sociais pela UFSCar. Endereço eletrônico: luci fabiana@yahoo.com

** Doutoranda em Antropologia pela UFRJ. Endereço eletrônico: virginiafes@hotmail.com

1 Nesta pesquisa de mestrado, trabalhamos com imigrantes italianos e negros ex-escravos no Oeste Paulista (São Carlos), nos anos seguintes à Abolição: 1890 a 1900. Procuramos esclarecer, por meio de uma análise qualitativa de depoimentos contidos em processos criminais da época, a lógica dos discursos elaborados por esses agentes sociais em situação de interlocução e convivência. Consideramos para análise os processos criminais que envolviam italianos e negros como réus ou vítimas e, feita a seleção, analisamos depoimentos tanto de réus e vítimas, como de testemunhas italianas ou negras envolvidas no conflito. Seus discursos se estruturam a partir de uma lógica diferenciada, e neste sentido, buscamos nas narrativas a presença de representações sociais, sempre pensando na interação entre eles. Essa pesquisa fez parte do projeto "Imigração, conflito cotidiano e violência interétnica no Oeste Paulista, 1882-1914", coordenado por Karl Monsma e Oswaldo Truzzi, e financiado pelo CNPq (processo 479959/2001-3) e pelo programa Brasil-Latino da Fundação Cassamarca.

2 Na pesquisa de doutorado em andamento, focalizamos as Ações Diretas de Inconstitucionalidade julgadas pelo STF entre os anos de 1988-2003, observando o comportamento do Tribunal como ator político, e analisando o voto de cada um dos ministros do tribunal, a fim de perceber se o perfil e a trajetória de carreira exercem influência sobre a forma como constroem seu posicionamento nas questões julgadas pelo Tribunal. O titulo da pesquisa é "Justiça, Profissão e Política: uma análise da atuação do STF no processo de consolidação da democracia no Brasil", e conta com o suporte financeiro da Fapesp e da Capes.
} 
são segmentos populares, imigrantes italianos e negros; no segundo, membros da elite política e jurídica do país. O artigo pretende ater-se à parte metodológica, não se detendo nas particularidades das pesquisas.

Se quisermos classificar o tipo de pesquisa feita a partir da utilização de processos judiciais, a primeira definição é a de pesquisa documental. Processos são documentos históricos e oficiais, e o trabalho com esses documentos traz, ao menos, duas implicações metodológicas: a questão do poder e a da interpretação. Estes questionamentos surgem principalmente quando se trabalha qualitativamente com os dados, quando a preocupação está em buscar a lógica e os códigos que estão informando as palavras para inferir sobre grupos sociais específicos.

Como se trata de um documento oficial, a questão do poder aparece porque o Estado pode ser considerado o verdadeiro produtor do que está escrito, encobrindo a expressão de qualquer grupo social que esteja contida no documento em forma de um depoimento, por exemplo, ou mesmo na argumentação do juiz que, além de membro de um dos poderes do Estado também pode ser visto como membro de uma corporação profissional. ${ }^{3}$ Já a questão da interpretação surge porque estamos trabalhando com o que está escrito e não, com o acontecimento em si, ou ainda porque não estamos interpretando por meio da observação direta, mas por meio da palavra escrita, e isto é fonte de inúmeros questionamentos, que envolvem a questão da subjetividade.

Antes de entrarmos nestas questões uma observação se faz necessária. O primeiro passo a ser dado em qualquer tipo de pesquisa é a definição precisa do objetivo, das questões que se quer responder. $\mathrm{O}$ interesse do investigador deve estar claro, bem discriminado, uma vez que a parte metodológica só poderá fazer sentido, se adequada aos objetivos e preocupações propostos.

3 O conceito de profissão e grupo profissional segue definição de Bonelli (2002). 
Definido o objetivo, dependendo do que a pesquisa propõe, os dados disponíveis podem ser trabalhados de formas diferentes, podem tanto ser quantitativa como qualitativamente analisados. Não se quer aqui ressaltar a superioridade de um ou outro método de pesquisa social, e vale lembrar a frase de Howard Becker, que trata a compreensão científica analogamente às peças de um mosaico. "Diferentes fragmentos contribuem diferentemente para a nossa compreensão: alguns são úteis por sua cor, outros porque realçam os contornos de um objeto. Nenhuma das peças tem uma função maior a cumprir" (Becker, 1993, p. 104).

A análise quantitativa pode propiciar não só uma "quantificação" de ocorrências - como quantidade de absolvições segundo o tipo de crime ou raça (no caso de processos criminais) ou quantidade de processos deferidos de acordo com o objeto da lei questionada ou de acordo com sua origem (no caso dos processos do STF) - como também uma análise mais sofisticada, trazendo à luz importantes relações entre os diversos atores e tópicos envolvidos.

Mas, como os questionamentos apontados anteriormente para discussão referem-se mais ao trabalho qualitativo que pode ser desenvolvido por meio das fontes documentais, será nele que vamos concentrar-nos. Optamos por trabalhar assim com as implicações da análise qualitativa, da análise que busca ações e associações feitas pelos agentes que têm sua fala registrada no processo. A preocupação está, então, na apreensão dos valores, regras e condutas que entram em jogo na luta simbólica em que estão envolvidas as representações do mundo social.

À medida que se atribui importância às interpretações que as pessoas fazem a respeito de um acontecimento ou assunto, isto implica um estudo mais particular, que entre em contato com especificidades, com o que é heterogêneo. Retomando o que foi posto por Bourdieu (1999), aqui se compreende que os sujeitos podem não deter a verdade objetiva de seu comportamento e que o discurso não é propriamente a explicação do com- 
portamento. Mas, conforme está sendo visto, importam mais as interpretações que as pessoas fazem para explicar um comportamento ou posição diante de um fato.

Assim, mesmo que o discurso seja também um aspecto do comportamento a ser explicado, o que certamente poderá ser feito a partir de uma construção teórica, entender a lógica de sua construção pode dizer-nos algo do que o grupo é. Especialmente porque nestes discursos encontramos representações sociais que podem mostrar-nos o modo como o grupo representa a si mesmo. Uma teoria estatística poderia indicar a presença e a circulação de representações, mas certamente pouco indicaria a respeito do que elas são para as pessoas que as empregam.

Pode-se dizer que a percepção do mundo depende em grande parte do que Bourdieu (1990) chama de habitus, ou seja, a internalização da estrutura que a pessoa experimenta e que faz com que as coisas não se apresentem a ela de maneira independente; há um modo de percepção dado pelo saber adquirido, que indica uma disposição incorporada. A verdade acaba sendo dada muito mais na compreensão das coisas do que nelas próprias.

Desta forma, mesmo que os discursos não detenham a verdade objetiva do comportamento, mesmo que não se veja neles a explicação do comportamento, mas sim um comportamento a ser explicado, a análise qualitativa das narrativas dos processos permite evidenciar o modo como as pessoas percebem elas mesmas e os outros, definindo-se e posicionandose no espaço social. Mesmo que o discurso não seja considerado explicação para o comportamento, ele permite a percepção do que está informando a ação e o posicionamento das pessoas enfocadas.

\section{A questão do poder}

Processos judiciais são documentos escritos, documentos oficiais, 
portanto implicam a utilização de uma linguagem específica e esta linguagem implica poder.

A linguagem, na acepção de Bourdieu (1996), é um instrumento de ação e de poder. O discurso, portanto, deve ser compreendido num sistema de trocas simbólicas, no qual dispõe de um valor e de um poder (capital lingüístico) inseparável da posição que o seu locutor ocupa na estrutura social. Para se efetivar, ele supõe a existência de um emissor legítimo que se dirige a um receptor legítimo e "legitimador" deste discurso (Bourdieu, 1996, p. 83).

Nesta perspectiva, pensando a manifestação dos juízes nos processos, pode-se dizer que cada um deles tem o "poder de falar e agir em nome do grupo", tem o poder de produzir o discurso da corporação, pelo qual e no qual ela vai ser reconhecida, expressando, com isto, a ideologia dominante no grupo. Ainda segundo Bourdieu (1990), a linguagem do Direito é a da retórica da autonomia, da impessoalidade, da neutralidade e da universalidade.

O efeito da neutralização é obtido por um conjunto de características sintáticas tais como o predomínio de construções passivas e das frases impessoais, próprias para marcar a impessoalidade do enunciado normativo e para constituir o enunciador em sujeito universal, ao mesmo tempo imparcial e objetivo. O efeito da universalização é obtido por meio de vários processos convergentes: o recurso sistemático ao indicativo para enunciar normas, o emprego (...) de verbos atestivos na terceira pessoa do singular do presente ou do passado composto que exprimem o aspecto realizado; (...) o uso de indefinidos ("todo o condenado") e do presente intemporal - ou do futuro jurídico - próprios para exprimirem a generalidade e a omnitemporalidade da regra do direito: a referência a valores transubjectivos que pressupõem a existência de um consenso ético (por exemplo, "como bom pai de família"); o recurso de 
fórmulas lapidares e a formas fixas, deixando pouco lugar às variações individuais (Bourdieu, 1990, p. 215216).

No caso dos processos criminais em que, além da fala do juiz, aparecem os depoimentos, é possível perceber as falas das testemunhas, a forma como constroem e organizam esses depoimentos. Como são pessoas comuns diante de uma instância de poder, pode-se questionar que a Justiça seria a verdadeira produtora das narrativas, não sendo possível apreender, por meio dos discursos das testemunhas, vítimas ou réus, uma lógica que diga respeito a um grupo social específico, já que sua fala estaria sendo filtrada pela Justiça: juízes, promotores e escrivãos. E este é um aspecto bastante enfatizado quando se trabalha com processos jurídicos, de que o que há nesses processos é o Estado falando, e todos os discursos do processo estariam mais propriamente sendo proferidos por ele. Expressariam, desse modo, o Estado exercendo o controle da sociedade por meio da produção de uma verdade. No caso dos processos criminais, a Justiça não constituiria apenas um filtro para a fala dos agentes sociais enfocados, mas seria a própria emissora do que lá está dito (Maggie, 1992, p. 85).

Isto faz com que qualquer grupo social estudado, seja ele popular ou mesmo uma elite constituinte desse Estado, perca a possibilidade de distinção enquanto grupo específico, por estarem eles diante de ou inseridos numa instituição que domina e produz a verdade por meio de seus instrumentos. Deve-se, sem dúvida, considerar a existência de uma ordem dominante que, por meio das elites produtoras de discursos, difunde uma série de representações e imagens amparadas por uma ordenação sociopolítica impressa em leis e instituições.

Mas há o modo de usar esta ordem dominante, o uso que os meios "populares" fazem dela. E, mesmo quando se trata de um grupo inserido no Estado, como é o caso dos ministros do STF, é possível perceber expressões que tentam ir contra essa ordem. Inúmeras vezes os ministros em 
seus votos procuram posicionar-se contra uma lei vigente ou contra interpretação corrente do direito, a fim de transformá-la. O fato é que os juizes não são atores neutros, ou meros porta-vozes do discurso oficial do Estado. Seus valores influenciam a sua atuação, e esta afirmação é praticamente um consenso, aparecendo até mesmo nos debates que os ministros travam durante os julgamentos, como por exemplo, na Ação direta de Inconstitucionalidade número 171, quando um dos ministros, Francisco Rezek, afirma que "a análise desse problema, com toda a sua possível tecnicalidade, tem essencialmente a ver com a posição ideológica de cada um de nós a respeito do tema substancial" (acórdão da ADIN 171,1993, p. 30). ${ }^{4}$

Não existe o discurso "uno" do poder, de um lado e, em face dele, um outro contraposto. Os discursos são blocos táticos num campo das correlações de força; "podem existir discursos diferentes e mesmo contraditórios dentro de uma mesma estratégia; podem ao contrário, circular sem mudar de forma entre estratégias opostas" (Foucault, 1985, p. 96-97, apud Maggie, 1992, p. 87).

Ao narrar sua interpretação sobre um caso, parece evidente que o depoente estará usando determinadas associações, valores, preconceitos e estigmas e que isto, de algum modo, estará registrado no processo. E no caso do discurso dos juízes, é possível perceber, ainda por trás dos efeitos da retórica da autonomia, impessoalidade e universalidade, que suas falas expressam um grupo social que também opera uma série de representações próprias e que tem especificidades de acordo com a trajetória de carreira de cada um.

Existe uma pluralidade de discursos, e, se não existe o discurso do poder de um lado, e de outro, seu contraposto, o que existem são discursos não homogêneos - embora alguns venham sendo mais hegemônicos que outros.

Mais hegemônicos porque consideramos que os processos judiciais 
são produzidos em um campo especifico - o campo jurídico - num espaço especifico - nos tribunais - e que cada agente ocupa uma posição fixada a priori nesse espaço, segundo a distribuição desigual de capital (social, econômico, político, cultural, simbólico). A partir de suas posições, os agentes vão travar lutas concorrenciais entre si, em torno de interesses específicos que caracterizam a área em questão. Nessas lutas, o que está em jogo é o monopólio da violência simbólica legítima, ou seja, o poder de impor nomeações, de impor "princípios de visão e de di-visão do mundo" (Bourdieu, 1990).

Embora o juiz seja a figura que vai "ordenar" os diversos discursos, na medida em que tem o poder de posse da palavra, é possível apreender a fala de outros grupos, das partes do processo e, no caso dos processos criminais, das testemunhas, a partir de seus depoimentos. Como já colocado, o que existe é um campo de lutas em movimento, e isto se reflete nas ações e reações dos agentes que lutam pela melhor definição de sua posição (Bourdieu, 1990, p. 82 e 85). As representações estão inseridas nesta interação instituída cotidianamente entre grupos definidos.

A fala dos atores e suas interpretações do evento variam segundo o grupo ao qual a pessoa pertence. Devemos insistir aqui na questão das representações e categorias do discurso porque não há realidade social que seja pré-discursiva. Não há nada que seja anterior às categorias discursivas, e da mesma forma, as representações são anteriores a qualquer coisa que possa existir, sendo, assim, fundamentais para criação dos próprios grupos.

Nas narrativas estão contidas representações sociais, e estas exprimem realidades coletivas, são coisas sociais e produto do pensamento coletivo. Ou seja, não estamos reduzindo as representações sociais à experiência individual, categorias de representação são essencialmente coletivas.

Por outro lado, é importante que não se recuse à consciência individual "o poder de perceber semelhança entre as coisas particulares que ela representa para si", mesmo que seja da sociedade que se tomem emprestado os fatos para, em seguida, projetá-los na representação do mundo que 
as pessoas fazem (Durkheim, 1978, p. 161 e 165). Representações são aquelas responsáveis por justificar, aos próprios indivíduos que as forjam, suas escolhas e condutas.

Assim, até as representações coletivas mais elevadas só ganham sentido à medida que comandam os atos das pessoas, que elaboram sua construção de mundo. Uma variedade de compreensões de representações se faz presente, a realidade acaba "contraditoriamente construída pelos diferentes grupos". Disto decorre uma série de discursos e práticas diferenciadas (Chartier, 1988, p. 23).

Para Howard Becker (1993), a representação do mundo varia "porque a organização social molda não somente o que é feito, mas também o que as pessoas querem que as representações façam" (Becker, 1993, p. 139). Desta forma, acredita-se que existem modos de representação que serão encarados como "maneiras que as pessoas usam pra contar o que pensam que sabem para outras pessoas que querem sabê-lo" (ibid., p.137). As representações e categorias do discurso são anteriores a qualquer realidade, elas justificam aos próprios indivíduos suas escolhas e condutas.

É provável que o depoente faça uso de associações, estereótipos e valores e, de algum modo, isso estará registrado no processo, assim como o fazem os juizes, apesar de obedecerem, em sua fala, à retórica jurídica.

Portanto, o processo não deve ser visto apenas como expressão do Estado, e este não deve ser visto como emissor dos depoimentos. É necessário considerar os filtros que a justiça impõe, mas não se deve considerar que a narrativa não contenha o modo como determinada pessoa vivencia sua realidade. O processo contém formulações dos diversos segmentos envolvidos e não apenas a do Estado.

\section{Processos como narrativas}

Antes de entrarmos nas implicações da interpretação dos processos, 
gostaríamos de abordar outra importante referência teórico-metodológica, o conceito de narrativa.

Uma referência interessante nesta área é o trabalho de Steinmetz (1992) sobre a relevância das narrativas na formação da classe trabalhadora. Embora o autor aborde a classe trabalhadora e aqui se esteja falando também de um grupo específico da elite (juízes), a maneira pela qual o autor focaliza as narrativas no processo de formação da classe é de grande utilidade para o objetivo aqui em questão.

A primeira definição que o autor dá à narrativa é a de um discurso estruturado em começo, meio e fim, que descreva algum tipo de mudança ou desenvolvimento, permeado por conflitos e explicações causais (Steinmetz, 1992, p. 490). Outras definições oferecidas por Steinmetz são as de Frederic Jameson (Steinmetz, 1992, p. 496), que define narrativa como uma das coordenadas abstratas ou vazias dentro da qual nós viemos a conhecer o mundo e a compreender e ordenar o que chamamos de experiência, e a de Bordwell e Thompson (Steinmetz, 1992, p. 497), definindo narrativa como uma cadeia de eventos em relações de causa e efeito acontecendo no tempo, que começa com uma situação que se desencadeia em uma série de seqüências em que, finalmente, uma nova situação surge e traz um fim à narrativa.

Após definir o que entende por narrativa, o autor afirma que a análise dos aspectos culturais da formação de classe deve focalizar as histórias que as pessoas contam sobre si mesmas, pois a construção dessas histórias é fortemente condicionada pela cultura e pela memória coletiva da classe à qual elas pertencem (Steinmetz, 1992, p. 490-491), sendo, portanto, um reflexo da ideologia desta classe.

Tendo por base uma discussão de Ira Katznelson (apud Steinmetz, 1992, p. 492-493) sobre a formação da classe trabalhadora, a qual ele divide em quatro níveis: 1) estruturação de classe a partir do desenvolvimento do capitalismo; 2) modos de vida, segundo as maneiras pelas quais as pes- 
soas organizam a vida em sociedade; 3) disposições compartilhadas, segundo os valores pelos quais pessoas na mesma posição de classe orientam seu comportamento, sendo orientações ideológicas e discursos compartilhados e 4) ação coletiva, pois as pessoas que compartilham disposições devem necessariamente atuar de maneiras similares, Steinmetz vai propor a quebra do terceiro nível do esquema analítico de Katznelson em três partes distintas: 1) em habitus (definição de Bourdieu), 2) em discursos, alguns dos quais tomam a forma de narrativas e 3) outras práticas. Afirma que discursos e outras práticas são gerados pelo habitus e que retroagem com ele.

O autor propõe a ênfase no aspecto discursivo da formação de classe, na maneira como se estruturam os discursos e no seu conteúdo. Retomando Thompson, afirma que existe uma ligação muito forte entre as narrativas e a ideologia de classe: "Ideologies tend to assume a narrative form: stories are told which justify the exercise of power by those who possess it - situating them within tales that recount the past and anticipate the future". (Thompson, apud Steinmetz, 1992, p. 495). Assim, na análise das narrativas é preciso perguntar como os eventos são definidos, quais os eventos são incluídos na narração e quais são excluídos e que princípios governam o processo de seleção (Steinmetz, 1992, p. 497).

O conceito de narrativa de Steinmetz vem a somar tanto com os de habitus e de campo de Bourdieu, quanto com os demais apresentados até aqui, no sentido de abordar os diversos discursos presentes nos processos judiciais, lembrando que eles estão social e historicamente localizados, podendo revelar a identidade almejada, construída e difundida pelos atores envolvidos nesses processos.

\section{A questão interpretação}

A partir do momento em que o que se busca é compreender o discurso situado em um contexto histórico, social e político específico, a antropologia interpretativa também fornece um referencial teórico-metodológico 
de grande utilidade. Um questionamento muito comum feito aos pesquisadores que trabalham com fontes documentais para uma análise qualitativa de grupos sociais específicos, é que não estamos lidando diretamente com os grupos, com os acontecimentos que os envolvem, não estamos empreendendo a observação direta como acontece na etnografia, mas estamos diante do texto escrito num documento oficial, o que traria implicações diversas, algumas das quais discutimos aqui.

Geertz (1978) afirma que "o homem é um animal amarrado às teias de significados que ele mesmo teceu assumindo a cultura como sendo essas teias e sua análise (...) como uma ciência interpretativa, à procura do significado" (Geertz, 1978, p. 15). Assim, ele toma o comportamento humano enquanto essencialmente simbólico, consistindo de sistemas entrelaçados de signos interpretáveis, cabendo ao pesquisador a tarefa de compreendê-los:

Descobrir as estruturas conceptuais que informam os atos de nossos sujeitos, o dito no discurso social, e construir um sistema de análise em cujos termos o que é genérico a essas estruturas, o que pertence a elas porque são o que são, se destacam contra outros determinantes do comportamento humano. Em etnografia o dever da teoria é fornecer um vocabulário no qual possa ser expresso o que o ato simbólico tem a dizer sobre ele mesmo - isto é, sobre o papel da cultura na vida humana (Geertz, 1978, p. 37).

Lemos o processo, como "lemos a cultura" no sentido de Geertz. Os comportamentos, posições tomadas nos processos, são investigados, procurando-se as "estruturas significantes em termo das quais (...) são produzidos, percebidos e interpretados", sem as quais não fariam o menor sentido (ibid., p. 17). A questão que se coloca aqui é que, no trabalho com narrativas de processos, não se está observando diretamente o fenômeno ou o ato empreendido. 
Porém, o próprio Geertz adverte: "o que chamamos de nossos dados são realmente nossa própria construção das construções de outras pessoas" (ibid., p. 18). Isto quer dizer que sempre que interpretamos aspectos de uma cultura, estamos efetuando uma interpretação que é de segunda ou terceira mão, nas palavras do próprio autor. Trabalhar com narrativas de processos exige que tal argumento seja considerado, pois o próprio registro já é, ele mesmo, uma interpretação.

O fato de o trabalho de campo ser realizado pela leitura dos processos não faz com que a ação que eles têm registrado não possa ser considerada uma ação simbólica, nos termos de Geertz, uma ação a ser interpretada, uma ação a ganhar sentido à medida que se descobre o que elas são para seus agentes. Quer-se atingir o ato de pensamento que produziu o discurso. Tem-se aqui a tarefa da interpretação de "expressões da vida que foram fixadas pela escrita" (Ricoeur, 1990, p. 18). Tal como coloca Geertz, considera-se a análise da cultura "como uma ciência interpretativa, à procura de significado" (Geertz, 1978, p. 15).

As pesquisas se inserem na questão da escrita e da interpretação, já que se quer trabalhar com o que está registrado em processos. Este registro inclui, tal qual na escrita etnográfica, uma tradução da experiência para a forma textual. É certo que a "escrita etnográfica encena uma estratégia específica de autoridade" (Clifford, 1998, p. 21), a qual pode ser largamente discutida, tal como fez James Clifford, mas que aqui não constitui o cerne da questão.

Sabe-se que um autor como Geertz tem a questão da etnografia como central no desenvolvimento de sua argumentação e se acredita que tal argumentação pode ser pensada, sob alguns aspectos, para a análise que se procura empreender com processos. Segundo Clifford, "Geertz, numa série de estimulantes e sutis discussões, adaptou a teoria de Ricoeur ao trabalho de campo antropológico" (Clifford, 1988, p. 39).

Ricoeur afirma que cada palavra utilizada por um agente recorre ao 
papel seletivo dos contextos: "veiculada por um locutor preciso e um ouvinte que se encontra numa situação particular", em que é posta em jogo "uma atividade de discernimento que se exerce numa permuta concreta de mensagens entre os interlocutores" (Ricoeur, 1990, p. 18-19). Trata-se propriamente da interpretação, que ocorre o tempo todo.

Geertz formula a questão: "como é possível que antropólogos cheguem a conhecer a maneira como um nativo pensa, sente e percebe o mundo?" (Geertz, 1997, p. 86). É preciso procurar e analisar as formas simbólicas (palavras, imagens, comportamentos) em cujos termos as pessoas realmente se representam para si mesmas e para os outros (ibid., p. 90).

Deve-se buscar "com quê" ou "por meio de quê", ou "através de quê" (...), os outros percebem (Geertz, 1997, p. 89). A partir das narrativas dos processos, pode ser buscado o significado para o significante que temos em mão, ou seja, considerando significante o conjunto de atos simbólicos, pretende-se, a partir da análise do discurso social, enquadrá-los de forma inteligível (Geertz,1978, p. 36). Sabe-se que não se chegará a nada diferente de uma construção própria de construções de outras pessoas, é o que a análise dos processos irá permitir.

É importante lembrar que uma das principais considerações a ser feita da antropologia interpretativa é a de que é extremamente necessário manter a análise das formas simbólicas atreladas ao contexto social no qual elas estão inseridas. Não se pode perder de vista que o exercício da interpretação dos significados do discurso depende das posições e do campo de poder em que estão inseridos todos os atores, tanto quem fala (pesquisador) quanto de quem se fala (pesquisado). Por isso, é necessário compreender o resultado da pesquisa como uma interpretação possível dentro de um contexto histórico específico.

As reflexões aqui abordadas contribuem para a constituição de algumas delimitações da pesquisa com processos judiciais, do que se pode buscar por meio deste trabalho de campo e sobre como os dados podem 
ser utilizados. Pela análise das narrativas dos processos judiciais, pode-se buscar aquilo que é transmitido com a ocorrência de determinados comportamentos e com o discurso sobre esses comportamentos, ou seja, podese apreender a lógica que informa tais comportamentos e discursos empreendidos pelos grupos sociais estudados.

\section{Referências}

BECKER, Howard. Métodos de Pesquisa em Ciências Sociais. São Paulo: Hucitec, 1993.

BONELLI, Maria da Glória. Profissionalismo e Política no mundo do Direito. São Paulo: EdUFSCar/Sumaré, 2002.

BOURDIEU, Pierre. O Poder Simbólico. São Paulo: Difel, 1990.

A Economia das Trocas Lingüísticas. São Paulo: Edusp, 1996.

A Economia das Trocas Simbólicas. São Paulo: Ed. Perspectiva, 2003.

BOURDIEU, Pierre, CHAMBOREDON Jean-Claude e PASSERON, Jean-Claude. A Profissão de Sociólogo: preliminares epistemológicas. (Trad. Guilherme João de Freitas Teixeira). Rio de Janeiro: Ed. Vozes, 1999.

CERTEAU, Michel de. A Invenção do Cotidiano: artes de fazer. trad. Ephraim F. Alves. Petrópolis: editora Vozes, 1999.

CHARTIER, Roger. A História Cultural Entre Práticas e Representações. Rio de Janeiro: Editora Bertrand Brasil, 1988.

CLIFFORD, James. Sobre Autoridade Etnográfica. In: GONÇALVES, José Reginaldo dos Santos (Org.). A Experiência Etnográfica: Antropologia e literatura no século XX. Rio de Janeiro: Ed. da UFRJ, 1998.

DURKEIM, Émile. Religião e Conhecimento. In: Rodrigues, José Albertino (Org.). Émile Durkheim: Sociologia. vol.1. São Paulo: Ática, 1978.

GEERTZ, Cliford. A interpretação das Culturas. Rio de Janeiro: Zahar, 1978. 
Do Ponto de Vista do Nativo: a natureza do entendimento antropológico. In O Saber Local: novos ensaios em antropologia interpretativa. (Trad. Vera Mello Joscelyne). Petrópolis: Ed. Vozes, 1997.

MAGGIE, Yvonne. Medo do Feitiço: relações entre poder e magia no Brasil. Rio de Janeiro: Arquivo Nacional, 1992.

ORTIZ, Renato (Org.). Pierre Bourdieu: coleção Grandes Cientistas Sociais. São Paulo: Ática, 1983.

RICOEUR, Paul. Interpretação e ideologias. Rio de Janeiro: Francisco Alves, 1990.

STEINMETZ, George. Reflections on the Role of Social Narratives in Work Class Formation: Narrative Theory in the Social Sciences. Social Science History, vol. 16, no 3, p. 489-516, Fall 1992.

Recebido: 22/10/2004

Revisão: 16/11/2004

Aceite final: 10/12/2004

\section{Resumo}

O artigo discute, a partir da experiência de pesquisa das autoras com processos criminais e constitucionais, a utilização de processos judiciais como fonte de dados, focalizando em duas implicações metodológicas principais, a questão do poder e a questão da interpretação. Abordando os processos judiciais como narrativas, demonstra-se como é possível discorrer sobre a construção do discurso empreendido por determinados grupos sociais envolvidos nesses processos.

Palavras-chave: processos judiciais, poder, interpretação, narrativa. 


\section{Lawsuits as data source: power and interpretation}

\section{Fabiana Luci de Oliveira \& Virgínia Ferreira da Silva}

The Article discusses, based on the interpretation of the authors' research experience with criminal and constitutional lawsuits, the use of lawsuits as data sources, focusing on two main methodological implications: the issue of power and the issue of interpretation. Approaching lawsuits as narratives, it demonstrates how it is possible to discuss the construction of discourse by some social groups involved in those lawsuits.

Key words: Lawsuits, Power, Interpretation, Narrative. 